\title{
Surgical repair for primary pulmonary vein stenosis: Single-institution, midterm follow-up
}

\author{
Guocheng Shi, MD, Zhongqun Zhu, MD, PhD, Huiwen Chen, MD, PhD, Haibo Zhang, MD, PhD,
}

Jinghao Zheng, MD, PhD, and Jinfeng Liu, MD

\begin{abstract}
Background: Primary pulmonary vein stenosis (PVS) is a rare congenital heart condition and carries a poor prognosis.

Methods: A retrospective review of 18 patients who underwent surgical therapy for primary PVS (2006-2014) was conducted. According to the degree of stenosis severity, the involved pulmonary veins (PVs) were divided into 3 categories: mild (34 veins), moderate (8), and severe (3). Pericardial patch venoplasty was used in 10 involved veins, endarterectomy in 11 , and sutureless pericardial marsupialization in 19.
\end{abstract}

Results: Median surgical age and weight were 19.8 (range: 7-100) months and 7.7 (range: $5.3-20.3) \mathrm{kg}$, respectively. Bilateral PVS was found in 10 patients $(56 \%)$, and unilateral in $8(44 \%)$. Moderate or severe stenosis was found more frequently in PVs on the left side $(P=.035)$. Multivein involvement was more common in patients age $\leq 18$ months than in older patients $(75 \%$ vs $20 \%, P=.054)$. No early operative death occurred. Median length of hospital stay was 16 (range: 8-60) days. One subsequent death occurred $(6 \%)$, at the 2-month follow up after discharge. Median follow-up time for the remaining patients was 29 (range: 291) months. Three of the 6 PVs treated for moderate stenosis, compared with 7 of the 34 treated for mild stenosis, developed restenosis, irrespective of the surgical strategy $(P=.153)$. Most surviving patients remained in relatively good condition, in New York Heart Association functional class I or II.

Conclusions: Detailed morphologic evaluation of each PV involved is a consideration for surgery, and is closely related to the prognosis. Moderate or severe primary PVS is worse than mild PVS, and no differences were found in effectiveness among endarterectomy, pericardial patch venoplasty, and sutureless pericardial marsupialization in treating primary PVS. (J Thorac Cardiovasc Surg 2015;150:181-8)

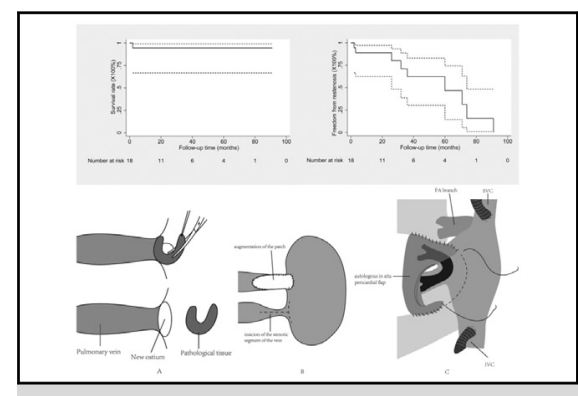

This figure shows 3 surgical techniques, and the overall prognosis in the median follow up.

\section{Central Message}

Detailed morphologic vein assessment is important for surgery and prognosis in PVS No differences were found in PVS treatment effectiveness among endarterectomy, patch venoplasty, and the sutureless technique.

\section{Perspective}

Use of the sutureless technique as a standard to treat primary pulmonary vein stenosis (PVS), based on effectiveness, is a subject of debate. Our findings indicate a close relationship between morphology and clinical prognosis, with moderate and severe primary PVS being worse than mild PVS. Endarterectomy and pericardial patch venoplasty should be used for treating mild stenosis, and the sutureless technique for moderate and severe PVS

See Editorial Commentary page 188.

\footnotetext{
From the Department of Cardiothoracic Surgery, Heart Center, Shanghai Children's Medical Center, Shanghai Jiaotong University School of Medicine, Shanghai, People's Republic of China.

This study was supported by Shanghai Hygiene Science Research (20134026), and a grant from the Shanghai Science and Technology Commission (14411964900).

Received for publication July 21, 2014; revisions received March 11, 2015; accepted for publication March 20, 2015; available ahead of print April 29, 2015.

Address for reprints: Zhongqun Zhu, MD, PhD, or Huiwen Chen, MD, PhD, Department of Cardiothoracic Surgery, Heart Center, Shanghai Children's Medical Center, Shanghai Jiaotong University School of Medicine, Dongfang Rd 1678, Shanghai, People's Republic of China (E-mail: zzqheart@aliyun.com or hwhwc@hotmail.com).

0022-5223/\$36.00

Crown Copyright (C) 2015 Published by Elsevier Inc. on behalf of The American Association for Thoracic Surgery

http://dx.doi.org/10.1016/j.jtcvs.2015.03.032
}

Primary pulmonary vein stenosis (PVS) with normal pulmonary venous connections is a rare congenital cardiac condition $(0.4 \%)$ and carries a poor prognosis. ${ }^{1}$ The clinical presentation can vary from local (discrete and ostial) stenosis, to diffuse stenosis, to atresia. Primary PVS is characterized by obstruction of the pulmonary venous blood flow as a result of hypoplasia of the pulmonary veins (PVs) or of constriction of the intima around the venous-atrial junction, which is caused by abnormal absorption of the common PV into the posterior wall of the left atrium in the later stages of cardiac development. $^{2}$

The condition generally leads to worsening pulmonary hypertension, and severe respiratory and cardiac failure in 


\section{Abbreviations and Acronyms \\ $\mathrm{PV}=$ pulmonary vein \\ PVS $=$ pulmonary vein stenosis \\ SPM $=$ sutureless pericardial marsupialization}

the pediatric population. Up to $80 \%$ of patients have another congenital heart abnormality, such as patent ductus arteriosus, atrial septal defect, and ventricular septal defects. ${ }^{3,4}$ These associated conditions elevate pulmonary blood flow and atrial load, which in turn promote PVS. ${ }^{5}$ From the histopathologic perspective, neointimal proliferation and medial hypertrophy have been described as main causative pathogenetic processes leading to occlusion of the luminal contour; proliferation of myofibroblast-like cells accounts for this progression. . $^{6}$

Treatments that include percutaneous and surgical intervention are, unfortunately, followed by progression of the disease, and restenosis within weeks to months, owing to the malignant obliterative disease biology, which is refractory to current therapeutic methods. ${ }^{9,10}$ Sutureless pericardial marsupialization (SPM) has been the preferred approach, in many centers, to relieve obstruction and reduce the restenosis rate; its indication has been extended from postrepair PVS to primary PVS. ${ }^{11-14}$ However, the results are inconclusive, especially in cases of upstream primary PVS, which usually is not amenable to SPM. ${ }^{15}$ The aim of the current study was to review our early and midterm outcomes of surgical correction for this malformation.

\section{METHODS \\ Patients}

We searched the cardiothoracic database of Shanghai Children's Medical Center, covering records from the 8-year period of October 2006 to February 2014 , for patients ( $n=18 ; 7$ were males) who presented with primary PVS and were referred to our center for surgical management. Eight patients diagnosed with primary PVS did not undergo surgical repair, owing to parental refusal in 4 cases, and a low severity (stenosis in a single PV) of isolated primary PVS in 3 cases. The other patient (age 6.5 months) unfortunately died in the cardiac care unit before the operation could be performed. These 8 patients were excluded from this study. Institutional review board approval was obtained, and perioperative data were collected and analyzed.

One patient had initial transcatheter closure of patent ductus arteriosus in the local hospital. Primary PVS was defined as anatomically normal pulmonary venous connections without previous surgery. Echocardiography was performed on all patients, and vessels were considered stenotic ${ }^{16}$ when the color Doppler technique revealed a turbulent, continuous flow with an abnormally high peak velocity $(>1.6 \mathrm{~m} / \mathrm{s})$. Angiographic computed tomography is a noninvasive procedure and can rapidly provide excellent images with good spatial resolution that can be used for diagnostic confirmation. Given that the echocardiography results did not reconcile with the computed tomography results in 4 patients, cardiac catheterization was performed.

Pulmonary vein atresia, representing the most severe end of the primary PVS spectrum, was defined either as complete obliteration of the lumen, extending $>5 \mathrm{~mm}$ within the involved veins on CT or catheterization, or as no demonstrable flow signal on echocardiogram. Table 1 shows the patient characteristics during the study period. Considering a combination of left-to-right-shunt anomaly, which can be associated with the promotion of PVS, and the presence of clinical symptoms, we took an aggressive approach in performing the operation in these patients.

Pulmonary hypertensive crisis was defined as having $\geq 1$ event in which the pulmonary arterial systolic pressure equaled or exceeded systemic levels, followed by a rapid decrease in systemic arterial pressure. Partial relief was defined as alleviating the obstruction, while the velocity of the addressed PVs remained at 1.2 to $1.6 \mathrm{~m} / \mathrm{s}$. Restenosis was defined as being either new stenosis after complete relief, progression of the stenosis after partial relief, or total occlusion of the atretic veins that were left unhandled.

\section{Evaluation of Obstructive PVs}

Morphologic assessment of the involved veins was made by computed tomography angiography or catheterization. In addition, intraoperative inspection played an important role in the evaluation. Upstream PVs were defined as veins near the pulmonary hilum, or extending into the periphery of the lung; downstream PVs were defined as veins localized proximal to the venoatrial junction, including the ostium. Three types of stenotic PVs were involved in our series. Type-I (mild) was stenosis occurring only at the ostial level or around the venoatrial junction, with a minimum PV diameter of approximately 2 to $4.5 \mathrm{~mm}$. Type-II (moderate) was tubular longsegment or diffuse hypoplasia of the PVs (both downstream and upstream), with a minimum $\mathrm{PV}$ diameter of $<2 \mathrm{~mm}$. Type-III (severe) was pulmonary vein atresia, such that the atretic veins could not be found, or only a few remnant tissues could be found intraoperatively.

A total of 45 PVs were stenotic. The frequency of involved PVs included the right upper $P V$ in 13 patients, the right inferior $P V$ in 9, the left inferior $\mathrm{PV}$ in 12, and the left upper PV in 11. Mild stenosis was found in most of the involved PVs $(\mathrm{n}=34)$, including 12 right upper, 8 right inferior, 7 left inferior, and 7 left upper. A moderate or severe degree of PVS was found in 11 $\mathrm{PVs}$, including 5 left inferior, 4 left upper, 1 right upper, and 1 right inferior, among which atresia was observed in 3 -right inferior, right upper, and left inferior. Moderate or severe stenosis of individual PVs was more commonly found in those on the left than those on the right ( 9 of 23, or $39 \%$, vs 2 of 22 , or $9 \% ; P=.035$ ).

Ten patients (56\%) had bilateral PVS, whereas 8 patients (44\%) had unilateral PVS, among whom 3 had stenosis of a single right upper PV. Of the 18 patients, $15(83 \%)$ had mild or moderate stenosis in the involved PVs. We found 6 patients $(75 \% ; 6$ of 8 ) in the infant cohort (age $\leq 18$ months), compared with 2 patients $(20 \% ; 2$ of 10$)$ who were diagnosed in late childhood (age $>18$ months), who had stenosis of 3 or 4 PVs $(P=.054)$. Four $(67 \%)$ of the 6 infant patients had moderate or severe stenosis.

\section{Surgical Technique}

All patients underwent surgical correction for primary PVS and associated defects after standard aorto-bicaval cardiopulmonary bypass was established. The procedures were performed under mild hypothermia, and myocardial protection was provided with cold 4:1 blood cardioplegia administered every 30 minutes during the ischemic time. In most patients, pulmonary venous return can be well controlled with pump suckers. However, facilitating exposure was difficult in 3 cases undergoing SPM, when we put the suturing line near the intraparenchymal portion. In these cases, a temporal reduction of bypass flow was adopted to provide a satisfactory intraoperative visualization.

Endarterectomy was performed in 11 stenotic veins. Exposure of the stenotic orifices of the individual PVs was attained through atriotomy. Two traction sutures placed on the pathologic tissue at the ostium, in the "12 o'clock" and "6 o'clock" directions, can help ease the resection of the tissue (Figure 1, A). For obstruction localized proximal to the PV ostia, we aggressively excised the stenotic ring (endocardial or fibrous) up to the tunica adventitia, and directly anastomosed the PV to the atrial endocardium, to ensure an unconstructed neo-orifice.

Pericardial patch venoplasty was used in 10 veins (Figure $1, B$ ). In this technique, the patch was anastomosed to the adventitia of the vein. 
TABLE 1. Patient characteristics

\begin{tabular}{|c|c|c|c|c|}
\hline Characteristic & $\mathbf{S P M}(\mathbf{n}=8)$ & Endarterectomy $(n=4)$ & Patch venoplasty $(n=6)$ & $P$ value \\
\hline Surgical age (mo) & $27.68 \pm 9.50$ & $19.13 \pm 8.88$ & $26.50 \pm 13.00$ & .836 \\
\hline Surgical weight $(\mathrm{kg})$ & $8.76 \pm 4.79$ & $8.93 \pm 2.34$ & $10.02 \pm 2.61$ & .815 \\
\hline Prematurity & $3(38)$ & $1(25)$ & $2(33)$ & 1.000 \\
\hline \multicolumn{5}{|l|}{ Associated cardiac lesion } \\
\hline PDA & $8(100)$ & $4(100)$ & $6(100)$ & NS \\
\hline ASD & $5(63)$ & $2(50)$ & $2(33)$ & .827 \\
\hline VSD & $4(50)$ & $2(50)$ & $2(33)$ & .846 \\
\hline PLSVC & $2(25)$ & $0(0)$ & $0(0)$ & .477 \\
\hline CAVSD & $1(13)$ & $0(0)$ & $0(0)$ & 1.000 \\
\hline DORV & $1(13)$ & $0(0)$ & $0(0)$ & 1.000 \\
\hline PABS (left/right) & $2(25)(1 / 1)$ & $1(25)(1 / 0)$ & $1(17)(1 / 0)$ & 1.000 \\
\hline \multicolumn{5}{|l|}{ Associated extracardiac lesion } \\
\hline Neural tube defect & $1(13)$ & $0(0)$ & $0(0)$ & 1.000 \\
\hline Bronchopulmonary dysplasia & $1(13)$ & $0(0)$ & $0(0)$ & 1.000 \\
\hline \multicolumn{5}{|l|}{ Initial clinical symptom } \\
\hline Recurrent pneumonias & $5(63)$ & $3(75)$ & $4(75)$ & 1.000 \\
\hline Failure to thrive & $3(38)$ & $1(25)$ & $2(33)$ & 1.000 \\
\hline Restriction in exercise capacity & $1(13)$ & $1(25)$ & $1(17)$ & 1.000 \\
\hline Hemoptysis & $0(0)$ & $1(25)$ & $0(0)$ & .222 \\
\hline Dyspnea & $1(13)$ & $0(0)$ & $1(17)$ & 1.000 \\
\hline Only murmur & $1(13)$ & $0(0)$ & $2(33)$ & .559 \\
\hline Bilateral involvement & $5(63)$ & $3(75)$ & $2(33)$ & .574 \\
\hline Only mild-form PVS & $4(50)$ & $4(100)$ & $3(50)$ & .279 \\
\hline
\end{tabular}

Surgical weight is given as mean $\pm \mathrm{SD}$; surgical age is given as mean \pm interquartile values. Other values are $\mathrm{n}(\%)$, except for $P$ values. $S P M$, Sutureless pericardial marsupialization; $P D A$, patent ductus arteriosus; $N S$, not significant; $A S D$, atrial septal defect; $V S D$, ventricular septal defect; $P L S V C$, persistent left superior vena cava to unroofed coronary sinus; CAVSD, complete atrioventricular septal defect; DORV, double outlet right ventricle; PABS, pulmonary artery branch stenosis; $P V S$, pulmonary vein stenosis.

Sutureless pericardial marsupialization (Figure 1,C) (alternatively called the sutureless technique) has been the procedure of choice, used in 19 stenotic veins, in more recent years. For SPM, the involved veins were incised longitudinally into their intraparenchymal portion; and 3 to $5 \mathrm{~mm}$ away from the pericardial reflection, pathologic or fibrotic tissue that seemed to have proliferative potential was excised as much as possible. Autologous in situ pericardial flaps were sewn distal to the incised veins, to serve as the hemostatic roof. If the stenosis was too close to the pulmonary hilum, excessive excision was avoided in case of intractable intrapleural bleeding Special care was taken to avoid injury to the phrenic nerves.

\section{Statistical Analysis}

Data were collected and analyzed with SPSS, version 18.0 (SPSS, Inc, Chicago, Ill). All results were expressed as frequency, median with range, or mean $\pm \mathrm{SD}$ or \pm interquartile range values, as appropriate. The significance of differences among the 3 groups was assessed by using the Fisher
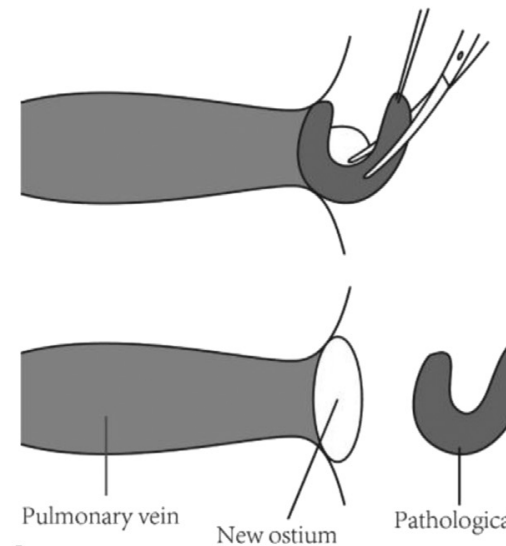

A

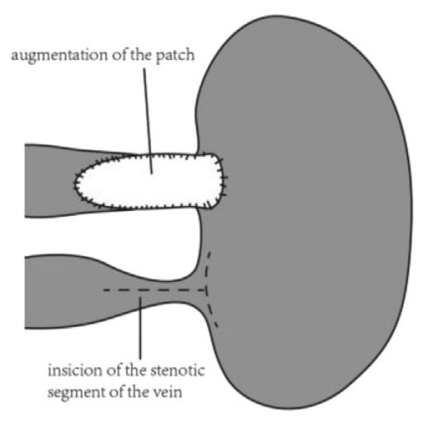

B

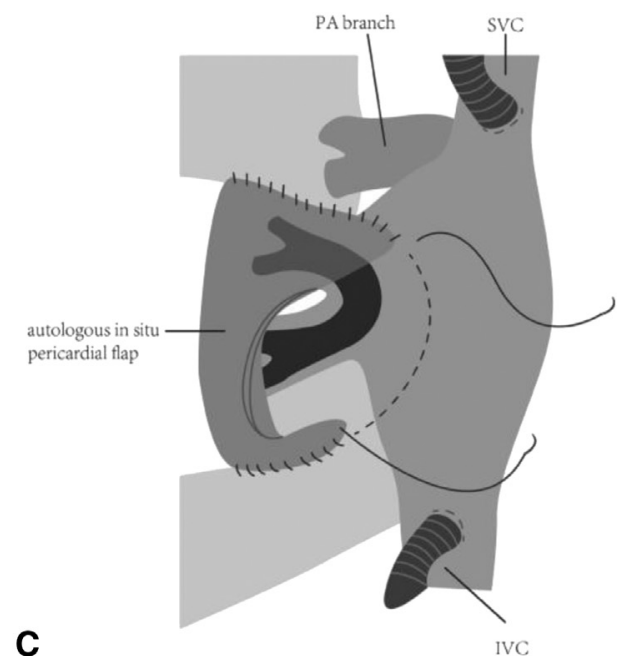

FIGURE 1. The figure shows: (A) resection of the stenotic ring to achieve an unconstructed neo-orifice; (B) a patch being anastomosed to enlarge the stenotic segment after resection of the stenotic tissue up to the tunica adventitia; and $(\mathrm{C})$ sewing of the autologous in situ pericardial flap, distal to the incised veins, to serve as the hemostatic roof. $P A$, Pulmonary artery; $S V C$, superior vena cava; $I V C$, inferior vena cava. 
TABLE 2. Detailed data of the 40 stenotic PVs treated with different surgical techniques

\begin{tabular}{|c|c|c|c|}
\hline Factor & $\begin{array}{c}\text { Endarterectomy } \\
(\mathbf{n}=11)\end{array}$ & $\begin{array}{l}\text { Patch venoplasty } \\
\quad(\mathbf{n}=10)\end{array}$ & $\begin{array}{c}\text { SPM } \\
(\mathbf{n}=19)\end{array}$ \\
\hline \multicolumn{4}{|c|}{ Immediate relief of stenotic PVs } \\
\hline Complete & $9(82)$ & $8(80)$ & $18(95)$ \\
\hline Partial & $2(18)$ & $2(20)$ & $1(5)$ \\
\hline \multicolumn{4}{|c|}{ Degree of stenosis before surgery } \\
\hline Mild & $11(100)$ & $7(70)$ & $16(84)$ \\
\hline Moderate & $0(0)$ & $3(30)$ & $3(16)$ \\
\hline Restenosis & $2(18)$ & $3(30)$ & $5(26)$ \\
\hline Reintervention & 0 & 0 & 0 \\
\hline
\end{tabular}

exact test and 1-way ANOVA. A simple Cox regression was used to test whether age is a risk factor for restenosis. Kaplan-Meier analysis was used to evaluate the survival rate and freedom from restenosis.

\section{RESULTS}

Mean cardiopulmonary bypass and ischemic times were $104.4 \pm 48.6$ minutes and $72.6 \pm 37.8$ minutes, respectively. The patency of the PVs was evaluated immediately by intraoperative transesophageal echocardiography, after weaning from cardiopulmonary bypass. Complete relief of obstruction was achieved with a median PV velocity of 1 (range, $0.7-1.2$ ) $\mathrm{m} / \mathrm{s}$ in 35 stenotic PVs (mild in 32 and moderate in 3); partial relief was attained in 5 veins (mild in 2, moderate in 3) (Table 2). The 2 moderate and 3 severe stenotic PVs were left unhandled, because either repairing the 2 moderate stenotic veins was difficult because they were extremely small, the atretic veins could not be found, or only a few tissue remnants were found intraoperatively.

No early operative mortality occurred. Delayed sternal closure was performed in 1 patient, owing to unstable hemodynamics. The median length of stay in the cardiac care unit, and the duration of ventilatory support were 4.7 (range, 1-52) days, and 27 (range, 5.5-264) hours, respectively. The average duration of hospital stay from the date of operation to discharge was 16 (range, 8-60) days. Two main complications contributed to an increase in hospital stay (60 and 34 days, respectively), including postoperative phrenic nerve palsy that necessitated bilateral diaphragm plication, in 1 patient who underwent bilateral SPM repair, and oliguria and peritoneal dialysis in another, who underwent patch venoplasty.

Follow up was available for $100 \%$ of the 18 patients, for a mean period of $33.6 \pm 27.1$ months. One subsequent death occurred after discharge from the hospital. This patient had a combination of primary PVS (atresia in the right inferior $\mathrm{PV}$, moderate stenosis in the left upper PV, and mild stenosis in the others) and complete atrioventricular septal defect. Bilateral sutureless repair for left inferior and right upper PVs, with a concomitant modified single-patch technique, was initially performed. The left upper and right inferior PVs were left unhandled.

Relief of luminal stenosis was acutely successful (velocity of $1.2 \mathrm{~m} / \mathrm{s}$ in both left inferior and right upper PVs); however, the patient developed progressive PVS in the right upper PV $(2.32 \mathrm{~m} / \mathrm{s})$, left upper PV $(2.26 \mathrm{~m} / \mathrm{s})$, and left inferior PV $(1.75 \mathrm{~m} / \mathrm{s})$ within 2 months and had moderate tricuspid regurgitation postoperatively. This patient was subsequently admitted to the department of cardiology, owing to recurrent pneumonias and dyspnea, and died of a pulmonary hypertension crisis after the failure of 3-day treatment.

The other 17 survivors were followed at intervals from 3 to 6 months, undergoing echocardiograms during the first 2 years after the initial operation, followed by annual assessment thereafter. Additionally, CT angiography was performed for detailed analysis of the PVs after surgical repair, in selective patients (Figure 2). Restenosis was found in 8 of the 17 surviving patients. Of these 8 patients, 3 were in New York Heart Association functional class II and had clinical symptoms that included hemoptysis (4 times in 2 years) in 1 patient, and recurrent upper respiratory tract infection in 2 patients. Class III was described in 1 patient $(12.5 \% ; 1$ of 8$)$, and class I in the other 4 patients $(50 \%$; 4 of 8).

We were conservative in deciding to perform reoperation, and continued to observe those patients who had restenosis. All of the 9 patients without restenosis were in good cardiac condition (New York Heart Association class I) at the last follow-up evaluation. Kaplan-Meier analysis of survival and restenosis after surgery is shown in Figure 3.

All of the 40 PVs, with either mild or moderate stenosis, were responsive to the surgical intervention within a short period. Among these, moderate progression of the stenosis was found in 50\% (3 of 6) of the PVs; in 21\% (7 of 34), mild progression was found, despite the initial complete or partial relief of the obstruction $(P=.153)$. Progression of stenosis was found to be greater in patients who had $\geq 1 \mathrm{PV}$ with more than mild stenosis, compared with those with only mild stenosis in all involved PVs $(100 \%$, or 7 of 7 , vs $18 \%$, or 2 of $11 ; P=.002$ ). Although the $P$ value was not statistically significant $(P=.172$; odds ratio: $1.077,95 \%$ confidence interval: $0.968-1.199)$, the trend seemed to be that progression of stenosis was more common in the infant cohort $(75 \% ; 6$ of 8$)$ than in those diagnosed at older ages $(30 \% ; 3$ of 10$)$.

\section{DISCUSSION}

This series presented a heterogeneous group of patients undergoing surgical intervention for primary PVS. Although the clinical characteristics of the patients assigned to either surgical strategy are not statistically different, selection bias may have played a role in the choice of operation. Sutureless pericardial marsupialization may have been 


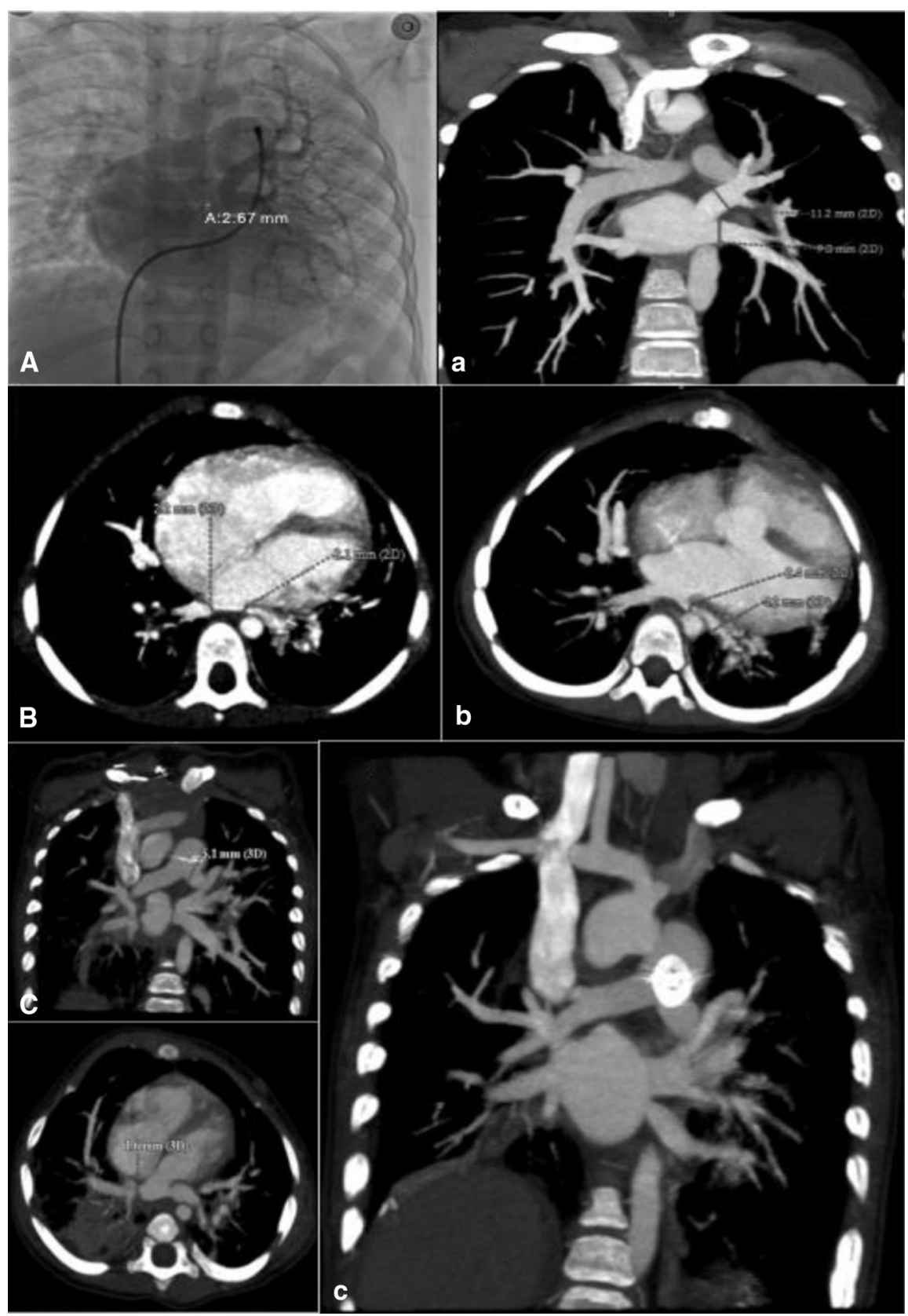

FIGURE 2. Evaluation of the PVs before and after surgical repairs. A, (Left) Stenosis occurs at the ostial level (2.67 mm) of the left PVs; (right) The diameters of the left PVs after endarterectomy are satisfactory. B, (Left) Stenosis occurs around the venous-atrial junction of both right and left veins; (right) Acceptable patency is achieved after patch venoplasty. C, (Left) Stenosis occurs at the ostial level of the left and right PVs; (right) The diameters of the left and right PVs after sutureless repair are satisfactory.

used more recently, particularly in the more challenging patients, and this factor may confound the results of this study.

Regardless of the type of surgical intervention, the restenosis rate was similar to that in the previous study, and the overall survival was higher than the reported rate ${ }^{4,10,17-19}$ of $48 \%$ to $86 \%$ (Table 3 ). These findings may be attributable to the fact that most patients had mild or moderate stenosis in the involved PVs, which usually has a more benign course. This series seems to trend toward older patients; possible explanations for this are that some patients may die before they consult a doctor, some infants were not offered surgery owing to their parents' refusal, and the cohort members were from different areas.

Many prior authors have suggested that associated anomalies could elevate the volume overload, which may be associated with a higher incidence of left PV involvement. ${ }^{5}$ 


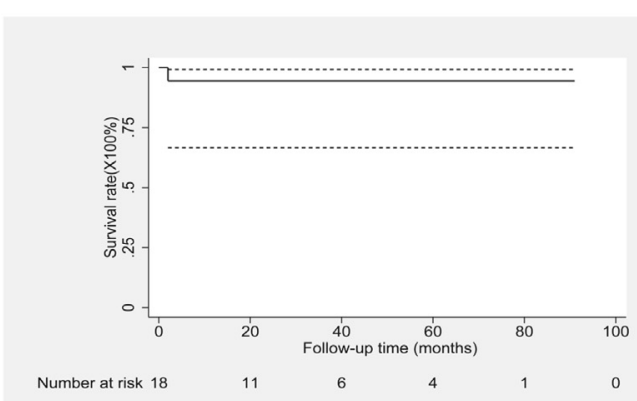

A

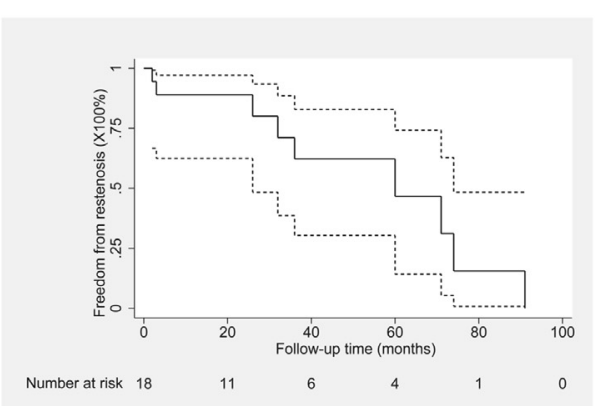

B

FIGURE 3. Kaplan-Meier analysis of (A) survival and (B) freedom from restenosis after the initial surgery. Solid line represents Kaplan-Meier estimates, with dashed lines enclosing $95 \%$ confidence limits.

According to the current cohort, no difference was found in the incidence of stenosis in left, versus right, PVs. Instead, a difference in degree of stenosis was found, with more severe stenosis in involved PVs on the left, compared with those on the right $(P=.035)$. Several explanations are possible. First, the associated cardiac lesions may ultimately lead to rotation of the heart on its axis, owing to the volume overload caused by intracardiac shunting. The rotation will further trap the stenotic left PV, especially the left inferior one.

Second, primary PVS is, in general, a progressive disease. The stenosis probably starts first on the left side, and a relatively long course of the disease may be associated with a more-severe degree of stenosis. A previous study ${ }^{3}$ mapped the first locus for primary PVS to $2 \mathrm{q} 35-2 \mathrm{q} 36.1$, in a family with 4 siblings. Fluoresence in situ hybridization or another gene study cannot be routinely performed, so the chromosome status was unknown in these sporadic cases, limiting their use in elucidating the potential etiology and pathophysiology of primary PVS.

The degree of stenosis with primary PVS varies. Based on 2-dimensional imaging and Doppler interrogation, Viola and colleagues ${ }^{18}$ used score criteria in classifying the severity of the stenotic PVs. They summed the scores obtained for each PV and deemed a preoperative score of $>4$ to be a predictor of mortality, despite surgical intervention. Compared with the previous study, more attention was paid to the distribution and morphology of the stenotic segment in each involved vein in this series.

TABLE 3. Reports of surgical outcomes for primary pulmonary vein stenosis

\begin{tabular}{lcccc}
\hline $\begin{array}{c}\text { First author } \\
\text { and date }\end{array}$ & $\begin{array}{c}\text { No. of } \\
\text { patients }\end{array}$ & $\begin{array}{c}\text { Mortality } \\
(\%)\end{array}$ & $\begin{array}{c}\text { Restenosis } \\
(\%)\end{array}$ & $\begin{array}{c}\text { Effectiveness of } \\
\text { sutureless technique }\end{array}$ \\
\hline Breinholt $^{4} 1999$ & 13 & 39 & - & Not effective \\
Devaney $^{21} 2006$ & 10 & 50 & 20 & Effective \\
Holt $^{10} 2007$ & 31 & 52 & - & Not effective \\
Azakie $^{17} 2011$ & 7 & 14 & 28 & Effective \\
Viola $^{18} 2011$ & 23 & 47 & 22 & Not effective \\
Song $^{20} 2013$ & 34 & 46.7 & 65.5 & Not effective \\
\hline
\end{tabular}

We categorized the stenosis into 3 degrees, as stated earlier. Individual PVs, of either mild or moderate stenosis, were responsive to the surgical intervention within a short time, but restenosis still developed in part of the PVs during the follow-up period. In addition, restenosis was found more often in PVs with moderate stenosis than in those with mild stenosis $(P=.153)$. Although no statistically significant difference was found, the results showed a concerning trend that stenosis of moderate degree was less amenable to surgical intervention, and therefore, potentially should be given a guarded prognosis. The lack of significance may be related to the small sample size.

Surgical techniques have evolved since Kawashima and colleagues $^{19}$ reported the first surgical repair of primary PVS. The conventional surgical intervention included endarterectomy and patch venoplasty; however, outcomes generally have been less than optimal. ${ }^{20}$ The newer SPM technique has now become the preferred approach in many centers, because it avoids stitching the cut edges of the PVs; this approach can thereby help prevent geometric distortion of the suture line and reduce the stimulus for regrowth of the obstructive tissue. ${ }^{14,21,22}$ However, the results are inconclusive for this procedure as well ${ }^{18,19,23,24}$ (Table 3).

In the current series, SPM can be performed to achieve acceptable midterm results in most mild or moderate stenotic veins, especially when 2 left or right PVs form 1 common PV ostium. Endarterectomy can provide an effective treatment by aggressive resection of the pathologic tissue in most mildly stenotic veins, and such resection seems to be unassociated with the overly exuberant growth of the proliferative myofibroblast-type cells in the PVs. Patch venoplasty produces satisfactory results in relieving mild stenosis, but carries a high rate of restenosis if the original stenosis is of moderate degree (Table 2).

\section{Summary}

Either of these techniques can be achieved with favorable outcomes in most PVs with mild stenosis. Although the 
difference between the results of SPM and patch venoplasty in repairing moderate stenotic veins is not statistically significant, the trend seems to be that SPM is associated with better outcomes and should be considered the first choice for these patients. Given that endarterectomy was performed in only mildly stenotic PVs, assessment of its effectiveness in repairing moderate-degree stenosis is difficult in the context of this study. Progression of the disease still cannot be avoided in some patients, especially in stenosis of more than mild degree.

Recently, Zhu and colleagues ${ }^{15}$ found that Losartan (Merck Sharp \& Dohme Ltd, Northumberland, UK) can ameliorate PVS-associated pulmonary hypertension and diffusely distributed intimal hyperplasia, which extends upstream into the intrapulmonary segment in a piglet model. Probably, a combination of surgical and medicine therapy will be key in future treatments. In a small number of patients with a severe degree of primary PVS, pneumonectomy may be necessary for unilateral PVs involved with massive hemoptysis, and lung transplantation may be ideal in cases of severe pulmonary hypertension. ${ }^{19,25}$

In this series, we observed a trend indicating that involvement of $\geq 3$ PVs was more frequent in younger patients, which was consistent with the study by Song and colleagues. ${ }^{20}$ In addition, greater severity of obstruction was more common in the cohort of infant patients, which likely can be explained by the nature of active proliferation of the involved PVs, or unpredictable progression to the healthy PVs. Among the patients undergoing surgery, 1 of the 8 patients with $>2$ stenotic PVs died, compared with no deaths in the remaining 10 patients with fewer involved PVs. Although the difference was not statistically significant $(P>.05)$, the trend corresponded with that found in previous research showing higher mortality in patients with 3 or 4 stenotic PVs, compared with patients with 1 or 2 stenotic PVs. ${ }^{4}$

Complex statistical analyses are difficult to perform, to draw a definitive conclusion regarding statistical power, owing to the small numbers involved. However, concern remains that moderate or severe PVS is associated with poor prognosis, and that such severity is more common in infancy-onset patients. In addition, the combination of PVS with complete atrioventricular septal defect is a risk factor for poor prognosis, possibly because of the insufficiency of the reconstituted atrioventricular valves, which elevates the atrial load and results in restenosis.

\section{Limitations}

First, this study was a retrospective review, so it is subject to selection bias, owing to the heterogeneity of the patients. Second, this single-institute series included a small group of patients and a small number of events, thus limiting the statistical power with which to draw firm conclusions and generalize the results. A larger series, with a randomized design and long-term follow up, is mandatory to confirm these preliminary data. Third, owing to the specifics of our health system and lack of health insurance, most patients' parents in this study could not afford the expense of cardiac catheterization; as a result, the pulmonary arterial pressure and the systemic pulmonary artery pressure ratio were not both calculated in all of the patients. Thus, the relationship between these 2 measures and clinical prognosis cannot be defined. Fourth, consent to tissue biopsy was not approved by the parents, so it could not be performed on all patients in this study. Further histopathologic studies are required to elucidate the mechanisms of primary PVS.

\section{Conflict of Interest Statement}

Authors have nothing to disclose with regard to commercial support.

The authors sincerely thank Professor Shijian Liu for his statistical assistance.

\section{References}

1. Edwards JE. Congenital stenosis of pulmonary veins. Pathologic and developmental considerations. Lab Invest. 1960;9:46-66.

2. Bini RM, Cleveland DC, Ceballos R, Bargeron LM Jr, Pacifico AD, Kirklin JW. Congenital pulmonary vein stenosis. Am J Cardiol. 1984;54:369-75.

3. Minich LL, Tani LY, Breinholt JP, Tuohy AM, Shaddy RE. Complete follow-up echocardiograms are needed to detect stenosis of normally connecting pulmonary veins. Echocardiography. 2001;18:589-92.

4. Breinholt JP, Hawkins JA, Minich LA, Tani LY, Orsmond GS, Ritter S, et al. Pul monary vein stenosis with normal connection: associated cardiac abnormalities and variable outcome. Ann Thorac Surg. 1999;68:164-8.

5. Endo M, Yamaki S, Ohmi M, Tabayashi K. Pulmonary vascular changes induced by congenital obstruction of pulmonary venous return. Ann Thorac Surg. 2000; 69:193-7

6. Sadr IM, Tan PE, Kieran MW, Jenkins KJ. Mechanism of pulmonary vein stenosis in infants with normally connected veins. Am J Cardiol. 2000;86:577-9.

7. Riedlinger WF, Juraszek AL, Jenkins KJ, Nugent AW, Balasubramanian S, Calicchio ML, et al. Pulmonary vein stenosis: expression of receptor tyrosine kinases by lesional cells. Cardiovasc Pathol. 2006;15:91-9.

8. Abe J, Deguchi J, Matsumoto T, Takuwa N, Noda M, Ohno M, et al. Stimulated activation of platelet-derived growth factor receptor in vivo in balloon-injured arteries: a link between angiotensin II and intimal thickening. Circulation. 1997; 96:1906-13.

9. Fong LV, Anderson RH, Park SC, Zuberbuhler JR. Morphologic features of stenosis of the pulmonary veins. Am J Cardiol. 1988;62:1136-8.

10. Holt DB, Moller JH, Larson S, Johnson MC. Primary pulmonary vein stenosis. Am J Cardiol. 2007;99:568-72.

11. Lacour-Gayet F, Zoghbi J, Serraf AE, Belli E, Piot D, Rey C, et al. Surgical management of progressive pulmonary venous obstruction after repair of total anomalous pulmonary venous connection. J Thorac Cardiovasc Surg. 1999;117: 679-87.

12. Najm HK, Caldarone CA, Smallhorn J, Coles JG. A sutureless technique for the relief of pulmonary vein stenosis with the use of in situ pericardium. $J$ Thorac Cardiovasc Surg. 1998;115:468-70.

13. Caldarone CA, Najm HK, Kadletz M, Smallhorn JF, Freedom RM, Williams WG, et al. Relentless pulmonary vein stenosis after repair of total anomalous pulmonary venous drainage. Ann Thorac Surg. 1998;66:1514-20.

14. Yun TJ, Coles JG, Konstantinov IE, Al-Radi OO, Wald RM, Guerra V, et al. Conventional and sutureless techniques for management of the pulmonary veins: evolution of indications from post repair pulmonary vein stenosis to primary pulmonary vein anomalies. J Thorac Cardiovasc Surg. 2005;129:167-74.

15. Zhu J, Ide H, Fu YY, Teichert A-M, Kato H, Weisel RD, et al. Losartan ameliorates 'upstream' pulmonary vein vasculopathy in a piglet model of pulmonary vein stenosis. J Thorac Cardiovasc Surg. 2014;148:2550-7. 
16. Smallhorn JF, Pauperio H, Benson L, Freedom RM, Rowe RD. Pulsed Doppler assessment of pulmonary vein obstruction. Am Heart J. 1985;110: 483-6.

17. Azakie A, Lavrsen MJ, Johnson NC, Sapru A. Early outcomes of primary sutureless repair of the pulmonary veins. Ann Thorac Surg. 2011;92:666-71.

18. Viola N, Alghamdi AA, Perrin DG, Wilson GJ, Coles JG, Caldarone CA. Primary pulmonary vein stenosis: the impact of sutureless repair on survival. J Thorac Cardiovasc Surg. 2011;142:344-50

19. Kawashima Y, Ueda T, Naito Y, Morikawa E, Manabe H. Stenosis of pulmonary veins: report of a patient corrected surgically. Ann Thorac Surg. 1971;12: 196-202.

20. Song MK, Bae EJ, Jeong SI, Kang IS, Kim NK, Choi JY, et al. Clinical characteristics and prognostic factors of primary pulmonary vein stenosis or atresia in children. Ann Thorac Surg. 2013;95:229-34.

21. Devaney EJ, Chang AC, Ohye RG, Bove EL. Management of congenital and acquired pulmonary vein stenosis. Ann Thorac Surg. 2006;81:992-5.
22. Lacour-Gayet F, Rey C, Planche C. Pulmonary vein stenosis. Description of a sutureless surgical procedure using the pericardium in situ. Arch Mal Coeur Vaiss. 1996;89:633-6.

23. Ricci M, Elliot M, Cohen GA, Catalan G, Stark J, de Leval MR, et al. Management of pulmonary venous obstruction after correction of TAPVC: risk factors for adverse outcome. Eur J Cardiothorac Surg. 1999;15:735-41.

24. Spray TL, Bridges ND. Surgical management of congenital and acquired pulmonary vein stenosis. Semin Thorac Cardiovasc Surg Pediatr Card Surg Annu. 1999;2:177-88

25. Mendeloff EN, Spray TL, Huddleston CB, Bridges ND, Canter CB, Mallory GB Jr. Lung transplantation for congenital pulmonary vein stenosis. Ann Thorac Surg. 1995;60:903-6.

Key Words: congenital heart disease, primary pulmonary vein stenosis, surgery

\section{EDITORIAL COMMENTARY}

\section{Primary pulmonary vein stenosis: Can we expect different results?}

Pirooz Eghtesady, MD, PhD

See related article on pages $181-8$.

Much has been written on the topic of acquired pulmonary vein stenosis (PVS) after repair of total anomalous pulmonary venous return (which still is an enigma); even less is known about primary PVS. In this issue of the Journal, Shi and colleagues ${ }^{1}$ from Shanghai, China, present their experience from the surgical treatment of 18 patients with primary PVS (in fact, 26 patients had been referred to their institution, but 7 in 8 did not undergo operation because of family refusal or mild severity of disease, and their longterm outcomes are unknown), making this one of the larger reports to date.

What we do know is that primary PVS is rare, often presenting in the setting of other defects with significant left to right shunting. There have been rare reports of its presentation in adults in isolation. ${ }^{2}$ In general, our knowledge of

From the Department of Pediatric Cardiothoracic Surgery, Washington University Medical School, St Louis, Mo.

Disclosures: Author has nothing to disclose with regard to commercial support.

Received for publication May 1, 2015; accepted for publication May 5, 2015.

Address for reprints: Pirooz Eghtesady, MD, PhD, Department of Pediatric Cardio-

thoracic Surgery, Washington University Medical School, Campus Box 8109, St

Louis, MO 63110 (E-mail: eghtesadyp@wudosis.wustl.edu).

J Thorac Cardiovasc Surg 2015;150:188-9

0022-5223/ $\$ 36.00$

Copyright (C) 2015 Published by Elsevier Inc. on behalf of The American Association for Thoracic Surgery

http://dx.doi.org/10.1016/j.jtcvs.2015.05.020 pulmonary vein biology lags that of the arterial side. This is changing rapidly, however, in part due to continuing rapid advances in molecular biology. Recently, a French group identified the EIF2AK4 (also known as GCN2) gene as the culprit for a form of veno-occlusive disease. ${ }^{3}$ The same gene was subsequently found

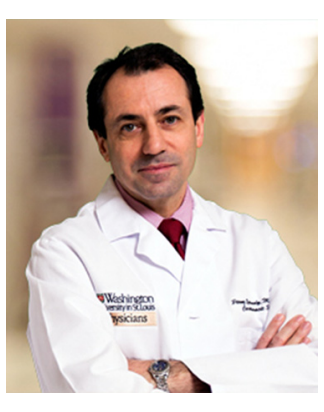
to be responsible for another closely related pathology, pulmonary capillary hemangiomatosis. ${ }^{4}$ In both, a form of uncontrolled endothelial and smooth muscle proliferative response leads to specific pathology on the venous side of the pulmonary circulation, not too dissimilar as seen in PVS.

Shi and colleagues report their outcomes after 3 different surgical procedures: patch venoplasty, endarterectomy, and the technique of marsupialization, or "sutureless" repair. Although the results are inconclusive, Shi and colleagues suggest that perhaps the marsupialization procedure is the most effective surgical solution. The median age of their patients was 20 months (survival of the fittest?), and their mean follow-up time was only 33 months. Finally, one of their figures (Figure 3,A) shows the sobering statistic that nearly all the patients in their series had development of restenosis. We all know how that story will end.

There is much we still don't know about this disease. For instance, as seen in this series, both prevalence and severity 